\title{
Patterns of triclosan resistance in Vibrionaceae
}

\author{
Keri A Lydon $^{1}{ }^{\text {, }}$ Megan Robertson ${ }^{1}$, Erin K. Lipp ${ }^{\text {Corresp. } 1}$ \\ ${ }^{1}$ Environmental Health Science, University of Georgia \\ Corresponding Author: Erin K. Lipp \\ Email address: elipp@uga.edu
}

The antimicrobial additive triclosan has been used in personal care products widely across the globe for decades. Triclosan resistance has been noted among Vibrio spp., but reports have been anecdotal and the extent of phenotypic triclosan resistance across theVibrionaceae family has not been established.Here, triclosan resistance was determined for Vibrionaceaestrains across nine distinct clades. Minimum inhibitory concentrations (MIC) were determined for 71 isolates from clinical $(n=6)$ and environmental sources $(n=65)$; only 2 were susceptible to triclosan. The mean MIC for all resistant Vibrionaceaewas $53 \mu \mathrm{g} \mathrm{mL}^{-1}$ (range 3.1-550 $\mathrm{g} \mathrm{mL}^{-1}$ ), but was significantly different between clades $(p<0.001)$. The highest mean triclosan MIC was observed in the Splendidus clade (200 $\left.\mathrm{g} \mathrm{mL}^{-1} ; \mathrm{n}=3\right)$. Triclosan mean MICs were $68.8 \mu \mathrm{g} \mathrm{mL}^{-1}$ in the Damselae clade and $45.3 \mathrm{mg} \mathrm{mL}^{-1}$ in the Harveyi clade. The lowest mean MIC was observed in the Cholerae clade with $14.4 \mu \mathrm{g} \mathrm{mL}^{-1}$, which was primarily represented by clinical strains. There were no significant differences in triclosan MIC among individual species or among environmental strains isolated from different locations. Overall, phenotypic triclosan resistance appears to be widespread across multiple clades of Vibrionaceae. 


\section{Patterns of triclosan resistance in Vibrionaceae}

2

3

4

5 Keri Ann Lydon ${ }^{\mathrm{a}}$, Megan Robertson ${ }^{\mathrm{a}}$, and Erin K. Lipp ${ }^{\mathrm{a} \#}$

6

7 Department of Environmental Health Science, University of Georgia, Athens, Georgia, USA ${ }^{\text {a }}$

8

9

10

11

12 \#Address of correspondence to Erin K. Lipp, elipp@uga.edu

13

14

15

16

17

18

19

20

21

22

23 


\section{Abstract}

25 The antimicrobial additive triclosan has been used in personal care products widely across the 26 globe for decades. Triclosan resistance has been noted among Vibrio spp., but reports have been 27 anecdotal and the extent of phenotypic triclosan resistance across the Vibrionaceae family has 28 not been established. Here, triclosan resistance was determined for Vibrionaceae strains across 29 nine distinct clades. Minimum inhibitory concentrations (MIC) were determined for 71 isolates 30 from clinical $(n=6)$ and environmental sources $(n=65)$; only 2 were susceptible to triclosan. The 31 mean MIC for all resistant Vibrionaceae was $53 \mu \mathrm{g} \mathrm{mL}^{-1}$ (range 3.1-550 $\mu \mathrm{g} \mathrm{mL}^{-1}$ ), but was 32 significantly different between clades $(\mathrm{p}<0.001)$. The highest mean triclosan MIC was observed 33 in the Splendidus clade $\left(200 \mu \mathrm{g} \mathrm{mL}^{-1} ; \mathrm{n}=3\right)$. Triclosan mean MICs were $68.8 \mu \mathrm{g} \mathrm{mL}^{-1}$ in the 34 Damselae clade and $45.3 \mu \mathrm{g} \mathrm{mL}^{-1}$ in the Harveyi clade. The lowest mean MIC was observed in 35 the Cholerae clade with $14.4 \mu \mathrm{g} \mathrm{mL}^{-1}$, which was primarily represented by clinical strains. There were no significant differences in triclosan MIC among individual species or among environmental strains isolated from different locations. Overall, phenotypic triclosan resistance appears to be widespread across multiple clades of Vibrionaceae.

39

40

41

42

43

44

45 
The bacterial Family Vibrionaceae is made up of 7 genera and 142 species, grouped into

23 distinct clades (Sawabe, Kita-Tsukamoto \& Thompson, 2007; Sawabe et al., 2013). These aquatic bacteria exhibit high amounts of gene exchange (Polz et al., 2006), and act as opportunistic pathogens to both humans and marine organisms. Common pathogenic species in humans include $V$. cholerae, $V$. vulnificus, $V$. parahaemolyticus, $V$. alginolyticus, and Photobacterium damselae; however, any member of the Vibrionaceae associated with clinical disease is nationally reportable in the U.S. under the Cholera and Other Vibrio Illness Surveillance (COVIS) program (U.S. Centers for Disease Control and Prevention (CDC), 2017). In some cases, these infections may lead to severe outcomes including fatal bouts of diarrhea due to dehydration or fatal septicemia in patients with compromised immune systems (Hlady and Klontz, 1996; Guerrant, Carneiro \& Dillingham, 2003; Menon et al., 2014). Antibiotics are commonly used for treatment, with varying success rates (Wong et al., 2015). The role of antibiotic resistance in these bacteria has been investigated in environmental and retail oysters (Han et al., 2007), with some studies suggesting widespread resistance to multiple antibiotics in some strains of Vibrionaceae from both clinical and environmental origin (Garg et al., 2000; Baker-Austin et al., 2009; Kitaoka et al., 2001).

Although there is a well-established line of research on the role of antibiotic resistance among Vibrio spp., there is comparatively little research on resistance to non-therapeutic antimicrobial biocides in personal care products, which are used ubiquitously. One such antimicrobial is triclosan (2,4,4'-tricloro-2'-hydroxydiphenyl ether), for which resistance has been noted in some Vibrio spp., including V. cholerae (Massengo-Tiasse and Cronan, 2008; 
70 the enoyl-acyl carrier protein reductase that triclosan targets through binding, leading to eventual

71 inhibition of fatty acid synthesis (Levy et al., 1999; Reiss et al., 2002; Massengo-Tiasse and

72 Cronan, 2008). FabV from $V$. cholerae was able to confer resistance to triclosan in E. coli clones

73 with the alternate enzyme, with up to 20-fold higher concentrations (up to $10 \mu \mathrm{g} \mathrm{mL}^{-1}$ ) required

74 to inhibit growth (Massengo-Tiasse and Cronan, 2008; Zhu et al., 2010). Other mechanisms of

75 triclosan resistance that may be present include the expression of alternative or mutated enzymes,

76 and/or the presence of efflux pumps, which has been noted in Pseudomonas aeruginosa, E. coli,

77 and Salmonella enterica (Chuanchuen, Karkhoff-Schweizer \& Schweizer, 2003; Braudaki and

78 Hilton, 2004; Yazdankah et al., 2006). In fact, triclosan has been demonstrated to both induce

79 antibiotic resistance in biofilms and benthic microbial communities (Nietch et al., 2013; Carey

80 and McNamara, 2015) and confer cross-resistance to other important antimicrobials, as was

81 found in Salmonella and E. coli (Braudaki and Hilton, 2004). Understanding the extent of

82 triclosan resistance in Vibrionaceae is important given that reported cases have increased by $54 \%$

83 since 2016 (Marder et al., 2018) and have nearly doubled since 1996 in the US (U.S. Center for

84 Disease Control and Prevention, 2016).

85 Research to date is limited to only a few studies but such evidence suggests that triclosan 86 resistance may be common among Vibrio (Massengo-Tiasse and Cronan, 2008; DeLorenzo et 87 al., 2016); however, there has been no attempt to systematically evaluate resistance patterns.

88 Here, we examined triclosan resistance across a range of species and clades within Vibrionaceae, 89 including environmental isolates, to provide a baseline for triclosan resistance in this group.

90

91

92

\section{Materials and Methods}

Vibrionaceae Isolates 
94 Culture Collection (ATCC) or courteously provided from the culture collection of Rita Colwell

95 (University of Maryland) (Supplemental Data File 1). Members of clades represented are

96 common human pathogens and include 7 isolates of clinical origin. In addition, 55 presumptive

97 Vibrionaceae isolates were collected from coastal surface waters on thiosulfate-citrate-bile salts-

98 sucrose (TCBS) agar plates during a previous study (Lydon et al., 2017). Isolates were obtained

99 from three coastal sites in the southeast U.S. between July and September 2014. Two stations

100 were in the lower Florida Keys, including an offshore site (Looe Key Reef in the Florida Keys

101 National Marine Sanctuary; 24.5449 N 81.40713 W; sampled under permit number FKNMS-

102 2010-131-A1) and an inshore residential canal (Doctors Arm, Big Pine Key, FL; 24.700294 N

$10381.351825 \mathrm{~W}$ ). The final station was Clam Bank Landing in North Inlet Estuary (Georgetown,

$104 \mathrm{SC} ; 33.333933 \mathrm{~N} 79.192913 \mathrm{~W})$. Triclosan concentrations at the time of sampling for these

105 locations were 103, 362, and 18 ng L-1, for Looe Key Reef, Doctors Arm Canal, and Clam Bank

106 Landing, respectively (Lydon et al., 2017).

107 Identification of environmental Vibrionaceae isolates

108 Presumptive Vibrionaceae isolates were identified by sequencing of the Hsp60 gene

109 (Thompson et al., 2005; Preheim, Timberlake \& Polz, 2011; Jesser and Noble, 2018). Pure

110 cultures were extracted by boiling lysis. Extracted DNA was quantified (NanoDrop 1000,

111 Thermo Scientific, Wilmington, DE) and diluted to $5 \mathrm{ng} \mu \mathrm{L}^{-1}$ before being subjected to PCR

112 amplification using primers H279 (5'-GAATTCGAIIIGGCIGGIGA(TC)GGIACIACIAC-3') and

113 H280 (5’-CGCGGGATCC(TC)(TG)I(TC)(TG)ITCICC(AG)AAICCIGGIGC(TC)TT-3’) (Goh

114 et al., 1996; Kwok et al., 2002; Thompson et al., 2005; Preheim, Timberlake \& Polz, 2005).

115 Amplification reactions contained $10 \mu \mathrm{L}$ of 5x Master Mix (New England BioLabs (NEB), 
116 Ipswich, MA; Final concentration $1 \mathrm{x}), 0.5 \mu \mathrm{M}$ of each forward and reverse primers, and $10 \mu \mathrm{L}$ of

117 DNA template with molecular grade water for a final volume of $50 \mu \mathrm{L}$ per reaction. PCR

118 conditions on the thermal cycler (T100 Thermal Cycler, BioRad Laboratories Inc.) were $95^{\circ} \mathrm{C}$

119 for $3 \mathrm{~min}$ for initial denaturation followed by 20 cycles of $30 \mathrm{sec}$ at $95^{\circ} \mathrm{C}, 30 \mathrm{sec}$ at $37^{\circ} \mathrm{C}, 1 \mathrm{~min}$

120 at $72^{\circ} \mathrm{C}$. The final extension step was $72^{\circ} \mathrm{C}$ for $2 \mathrm{~min}$. Amplicons were purified using equal

121 volume SPRI magnetic beads (Sera-Mag SpeedBeads, Thermo Scientific, Freemont, CA)

122 (Rohland and Reich, 2012) with 96 well magnetic plate (Promega MagnaBot II) and stored at -

$12320^{\circ} \mathrm{C}$. Samples were sent to the Georgia Genomics and Bioinformatics Core (GGBC) (Athens,

124 GA) and sequenced by Sanger sequencing (Applied Biosystems 3730xl 96-capillary DNA

125 Analyzer).

126 To determine presumptive Vibrionaceae isolate identity, sequencing reads were loaded

127 into Geneious (version R11) and checked for quality before being subjected to BLAST (Pearson

128 and Lipman, 1988) against the chaperone database (cpnDB) by selecting for non-redundant

129 group I sequences (hsp60) (http://cpndb.ca/; Accessed May 02, 2018). Subsequently, isolates

130 were classified by clade and presumptive species by their closest cpnDB BLAST match. Isolate

131 sequences were aligned with MUSCLE in Unipro UGENE v.1.26.3 (Edgar et al., 2004;

132 Okonechnikov et al., 2012). The resulting alignment was used to build a phylogenetic tree using

133 PhyML maximum likelihood with aLRT SH-like branch support (Guindon et al., 2010). The

134 resulting tree was visualized using iTOL (version 4.0.3) and used in conjunction with BLAST

135 match to identify closest Vibrionaceae clade (Letunic and Bork, 2007; Fig. 1). All sequences

136 were submitted to NCBI GenBank with the BankIt submission tool (accession nos. MG975785-

137 MG975835). The matching accession no. for each isolate can be found in the supplemental data 138 file. 
139

140

141

142

143

144

145

146

147

148

149

150

151

152

153

154

155

156

157

158

159

160

161

\section{Triclosan MIC screening}

All isolates were screened for triclosan minimum inhibitory concentrations (MIC) using modified broth microdilution assays (Clinical and Laboratory Standards Institute (CLSI, 2012). Isolates were grown overnight at $30^{\circ} \mathrm{C}$ with shaking (130 rpm; Classic Series C-24 Incubator Shaker, New Brunswick Scientific) in $2 \mathrm{~mL}$ of $1 / 2$ strength Marine Broth (Zobell Marine Broth 2216 , HiMedia) $+\mathrm{NaCl}$ (Final concentration $0.972 \%$ ), after which $1 \mathrm{~mL}$ of growth was transferred to $4 \mathrm{~mL}$ of fresh Muller Hinton Broth $+\mathrm{NaCl}$ (Final concentration 2\%) and continued to incubate at $30^{\circ} \mathrm{C}$ for $4 \mathrm{~h}$ (with shaking at $130 \mathrm{rpm}$ ) to achieve log phase growth. E. coli (ATCC 15597) was also screened in the same manner as Vibrio isolates, but grown in LB broth in place of $1 / 2$ strength Marine Broth. This isolate served as a triclosan positive control given that E. coli is susceptible to triclosan (McMurry, Oethinger \& Levy, 1998; Lambert and Pearson, 2000). Cultures were adjusted to $0.5 \mathrm{McF}$ arland Standard in Muller Hinton Broth and exposed to eight triclosan concentrations, ranging from $0.78 \mu \mathrm{g} \mathrm{mL}^{-1}$ to $100 \mu \mathrm{g} \mathrm{mL}-1$ (in two-fold dilutions), in duplicate, with a final broth volume of $200 \mu \mathrm{L}$. Triclosan working stock $\left(0.8 \mathrm{mg} \mathrm{mL}^{-1}\right)$ was prepared by dissolving triclosan (Irgasan, $\geq 97.0 \%$ HPLC, Sigma Aldrich) into 100\% ethanol (Decon Laboratories). The final assay was conducted in UV-sterilized 96-well low binding plates (SiliGaurd, Analytical Sales and Services, Inc). In addition to triclosan exposures, each plate included two negative controls (sterile Muller Hinton Broth and 10\% Ethanol), as well as isolates without exposure to triclosan, in duplicate. The plates were placed at $120 \mathrm{rpm}$ in a shaking incubator at $30^{\circ} \mathrm{C}$ and read at $48 \mathrm{~h}$.

The lowest triclosan concentration in which there was no bacterial growth was noted as the MIC. The MIC concentrations for each replicate exposure were averaged. Those isolates that had MICs greater than $100 \mu \mathrm{g} \mathrm{mL}^{-1}$ were further screened at higher concentrations by streaking 
162 directly onto Muller Hinton Agar $+2 \% \mathrm{NaCl}$ agar plates containing final triclosan concentrations

163 of $0,50,100,200,300,400,500,600$, and $700 \mu \mathrm{g} \mathrm{mL}-1$. All assays were completed in duplicate.

164 Agar plates were used in place of broth due to the hydrophobic properties of triclosan and a

165 tendency for triclosan to precipitate out of solution at higher concentrations.

166 Classification of susceptible and resistant bacteria by MIC value is normally determined

167 by evaluation of an antibiotic's properties including screening of MICs across a large subset of

168 bacterial types (Sirot, Courvalin \& Soussy, 1996). However, triclosan MIC data are limited and

169 to our knowledge there is no published consensus on a cut-off level for resistant or susceptible

170 MIC levels. Thus, we classified triclosan resistance in this study as any isolate exhibiting a

171 triclosan MIC concentration higher than what was observed in our E. coli control, or greater than

$172 \quad 3.1 \mu \mathrm{g} \mathrm{mL}^{-1}$.

173 fabV in Published Vibrionaceae Genomes

174 To investigate how widespread $f a b V$ was in published Vibrionaceae genomes, a

175 nucleotide BLAST was conducted against the NCBI complete prokaryote genome database

176 selecting only for those genomes classified as Vibrionaceae (taxid:641).

177 Statistical Analyses

178 Triclosan MIC readings were log-transformed to approximate a normal distribution.

179 Results of the D'Agostino \& Pearson normality test indicated that log-transformed data were 180 normally distributed $(\mathrm{K} 2=4.09, \mathrm{p}=0.1294)$. Triclosan readings were checked for the assumption

181 of equal variances using the Brown-Forsythe test. Equal variances were found for all comparison

182 types: by species $\left(\mathrm{F}_{2,27}=0.2743, \mathrm{p}=0.7622\right)$, location $\left(\mathrm{F}_{2,51}=0.42, \mathrm{p}=0.6558\right)$, and clade

$183\left(\mathrm{~F}_{3,47}=1.589, \mathrm{p}=0.2046\right)$. Having passed both assumptions of normality and equal variance, log-

184 transformed triclosan MICs were compared using one-way ANOVA to determine differences 
185 amongst species, locations, and clades. For analysis of MIC by species, isolates were included in

186 a species group if their BLAST closest match was greater than 97\% identity (Supplementary

187 Data File) and there were more than three isolates available.

188

189

190

191

192

193

194

195

196

197

198

199

200

201

202

203

204

205

206

207

\section{Results}

\section{Triclosan Minimum Inhibitory Concentrations}

The mean triclosan MIC observed for all Vibrionaceae isolates $(\mathrm{n}=71)$ was $53 \mu \mathrm{g} \mathrm{mL}^{-1}$

with a range of 3.1-550 $\mu \mathrm{g} \mathrm{mL}^{-1}$. Over 97\% (69/71) of isolates showed phenotypic triclosan

resistance (>3.25 $\mu \mathrm{g} \mathrm{mL}^{-1}$ ) (Fig. 2). Only two Vibrionaceae isolates, both of which were

collected from environmental sources, were susceptible to triclosan: Photobacterium sp. strain

CB 6 (Damselae clade) from Clam Bank, SC and Vibrio sp. strain DA 5 (Cholerae clade) from

Doctors Arm, FL. MICs of $\leq 100 \mu \mathrm{g} \mathrm{mL}^{-1}$ of triclosan was required to inhibit growth for $90 \%$ of isolates. There were 11 isolates that exhibited elevated levels of resistance $\left(\geq 100 \mu \mathrm{g} \mathrm{mL}^{-1}\right)$ to triclosan. These isolates belonged to both the Photobacterium and Vibrio genera and came from all three of our environmental sampling sites. The highest triclosan MIC $\left(550 \mu \mathrm{g} \mathrm{mL}^{-1}\right)$ was observed in Vibrio sp. strain LK 11 (closest clade was Splendidus; hsp60 sequence 90.30\% identity with Vibrio crassostreae NZ_AJZC01000106) isolated from surface water at Looe Key Reef.

Triclosan MICs were compared by clade for those clades that included more than three isolates. Results of one-way ANOVA indicated significant differences in mean triclosan MICs for the Cholerae, Damselae, Harveyi, and Splendidus clades $\left(F_{3,47}=4.615, p=0.0065\right)$. Mean MICs were $14.4 \mu \mathrm{g} \mathrm{mL}^{-1}, 68.8 \mu \mathrm{g} \mathrm{mL}^{-1}, 45.3 \mu \mathrm{g} \mathrm{mL}^{-1}$, and $200 \mu \mathrm{g} \mathrm{mL} \mathrm{m}^{-1}$ for the Cholerae (n=5), Damselae ( $n=4)$, Harveyi ( $n=39)$, and Splendidus $(n=3)$ clades, respectively (Fig. 3). Post-hoc 
208 multiple comparisons (Tukey's Multiple Comparisons Test) indicated significantly lower

209 triclosan MICs for the Cholerae clade in comparison with Harveyi (adjusted p-value=0. 0283)

210 and Splendidus clades (adjusted $p$-value $=0.0149$ ), and Damselae (adjusted $p$-value $=0.0178$ ). Of

211 these clades, Splendidus exhibited the widest range of triclosan MIC readings (25-550 $\mu \mathrm{g} \mathrm{mL}^{-1}$;

$212 \mathrm{n}=3$ ) while Cholerae, primarily from clinical sources, showed the smallest range (3.1-18.8 $\mu \mathrm{g}$

$\left.213 \mathrm{~mL}^{-1} ; \mathrm{n}=6\right)$.

214 When examining environmental isolates based on where they were obtained, there were

215 no significant differences in mean triclosan MICs among the three stations (Fig. 4; $F_{2,51}=1.346$,

$216 \mathrm{p}=0.2694)$. There were no significant differences in triclosan MICs for environmental

217 Vibrionaceae among presumptive species in the Harveyi Clade (when there were more than three

218 isolates per species; clinical isolates excluded $)\left(\mathrm{F}_{2,27}=0.2743, \mathrm{p}=0.7622\right)$. Mean triclosan MICs

219 were $54 \mu \mathrm{g} \mathrm{mL}^{-1}$ for $V$. alginolyticus $(\mathrm{n}=14), 40 \mu \mathrm{gL}^{-1}$ for $V$. campbellii $(\mathrm{n}=5), 37.5 \mu \mathrm{g} \mathrm{mL}^{-1}$

220 for $V$. harveyi (n=11) (Fig. 5). Of these presumptive species, V. alginolyticus exhibited the

221 widest range of triclosan MIC readings $\left(9.4-200 \mu \mathrm{g} \mathrm{mL}^{-1}\right)$, while the smallest range was

222 observed in V. campbelli $\left(12.5-75 \mu \mathrm{g} \mathrm{m}^{-1}\right)$.

223 Investigation of $f a b V$ in whole genome sequences of Vibrionaceae resulted in 119

224 significant hits for the $f a b V$ gene within 131 published closed Vibrionaceae genomes. This

225 demonstrated that $f a b V$ typically occurs in Vibrionaceae but is not universal. In addition, $f a b V$

226 appeared to occur on either chromosome I or II, though occurring most frequently on

227 chromosome I.

228

229

\section{Discussion}


231 isolates through measurement of MICs. Results suggest that members of Vibrionaceae are

232 broadly resistant to triclosan across three genera (Vibrio, Allivibrio, and Photobacterium), nine

233 clades (Cholerae, Coralliilyticus, Damselae, Fischeri, Halioticoli, Harveyi, Orientalis,

234 Splendidus, and Vulnificus), and 15 species (A. fischeri, V. alginolyticus, $V$. brasiliensis, $V$.

235 campbellii, $V$. cholerae, $V$. coralliilyticus, $V$. furnissii, $V$. harveyi, $V$. mimicus, $V$.

236 parahaemolyticus, $V$. pelgaius, V.rotiferianus, $V$. splendidus, V. vulnificus, and P. damselae).

237 Furthermore, these included known pathogens (e.g., clinical strains from established culture

238 collections), as well as recently collected environmental isolates from distinctly different

239 ecosystems with variable amounts of anthropogenic impacts (Lydon et al., 2017).

Triclosan resistance was previously documented in V. cholerae (Massengo-Tiasse and

241 Cronan, 2008) and was suspected in unidentified Vibrio spp. from the estuarine environment

242 (DeLorenzo et al., 2016), but resistance had not been systematically examined across a wide

243 range of Vibrionaceae. Moreover, to our knowledge, this is the first study to report phenotypic

244 triclosan resistance in the closely related genus Photobacterium, which include species that are

245 both human and fish pathogens (e.g., P. damselae) (Rivas, Lemos \& Osorio, 2013). We also note

246 that the highest triclosan resistance MIC was observed in a presumptive $V$. crassostreae isolate,

247 an emerging shellfish pathogen (Bruto et al., 2017). Triclosan MICs demonstrated here for

248 Vibrionaceae are consistent with MICs reported for known triclosan resistant bacteria, including

249 Pseudomonas aeruginosa and Staphylococcus aureus (MICs ranging from 5 to greater than

250 2,000 $\mathrm{g} \mathrm{mL}^{-1}$ ) (Chuanchuen, Karkhoff-Schweizer \& Schweizer, 2003; Zhu et al., 2010).

251 There is growing evidence that Vibrio could be enriched in coastal waters by

252 pharmaceutical wastes and antimicrobial agents in personal care products (Peele et al., 1981; 
253 Grimes, Singleton \& Colwell, 1984; DeLorenzo et al., 2016; Lydon et al., 2017). Triclosan

254 resistance has specifically been hypothesized as a potential factor leading to increased abundance

255 of Vibrio bacteria after exposure of seawater or marine organisms to triclosan (DeLorenzo et al.,

256 2016; Lydon et al., 2017). V. alginolyticus demonstrated MICs up to $200 \mu \mathrm{g} \mathrm{mL} \mathrm{m}^{-1}$ and are an

257 emerging cause of vibriosis cases in the US, with infections increasing by 12-fold from 1996 to

258 2012, the highest rate of any Vibrio (Slifka, Newton \& Mahon, 2017). Triclosan has the capacity

259 to induce cross- or multiple- antibiotic resistance (Nietch et al., 2013; Carey and McNamara,

260 2015); therefore, we suspect there are risks of inducing resistance in the environment as

261 Vibrionaceae have plastic genomes and high gene transfer rates (Polz et al., 2006; Quirke et al.,

262 2006).

263 We observed significant differences in MIC between Vibrio at the Clade level, suggesting

264 that there may be some evolutionary role in resistance; however, much of this difference was

265 driven by low MICs among the Cholerae clade, which was over-represented by clinical strains

266 compared to other clades. Furthermore, differences were not observed between species, which

267 may support the alternate hypothesis that triclosan resistance may be ubiquitous among Vibrio

268 but may occur through multiple mechanisms. Triclosan resistance has previously been identified

269 in $V$. cholerae through the expression of a FabI analog, FabV, which prohibits triclosan from

270 binding and interrupting fatty acid synthesis (Massengo-Tiasse and Cronan, 2008). Analysis of

271 published closed whole genome sequences confirmed that fabV is highly associated with Vibrio

272 spp., including non-cholerae species, but also demonstrated that is it not universal among

273 Vibrionaceae genomes. We suspect the wide variability in triclosan resistance for Vibrionaceae

274 is due to the presence of multiple resistance pathways, including the presence of FabV,

275 overexpression of FabI, and efflux pumps that may be acting singularly or synergistically. These 
276 are particularly important as they could confer resistance to other antibiotics, which could have

277 significance for clinical applications.

278

279

280

Triclosan resistance appears to be nearly universal across Vibrionaceae isolates tested in

281

this study. Levels of resistance (MICs) were distinguishable between Vibrionaceae clades,

282 suggesting that some level of resistance is dependent on phylogeny, rather than environmental source, which showed no difference in MICs. This work is important in that it provides a broad examination of phenotypic resistance to this persistent antimicrobial compound among this group of potential pathogens. However, future investigations are needed to establish why triclosan resistance is so variable across the Vibrionaceae. We suspect the wide variability is likely due to multiple resistance mechanisms, which could have broader implications for emergence of antibiotic resistance.

Acknowledgements. We thank M Ghazaleh Bucher, K Kemp, D Kemp, A Oladeinde, RS

Rozier, J Westrich, M Edwards, K Herrington, and K Isaak for their assistance and advice.

\section{References}

Baker-Austin C, McArthur JV, Lindell AH, Wright MS, Tuckfield RC, Gooch J, Warner L, 
297 Braoudaki M, Hilton AC. 2004. Low level of cross-resistance between triclosan and antibiotics

298 in Escherichia coli K-12 and E. coli O55 compared to E-coli O157. FEMS Microbiology

299 Letters 235:305-309.

300 Bruto M, James A, Petton B, Labreuche Y, Chenivesse S, Alunno-Bruscia A, Polz MF, Le Roux

301 F. 2017. Vibrio crassostreae, a benign oyster colonizer turned into a pathogen after plasmid

302 acquisition. The ISME J. 11:1043-1052.

303 Carey DE, McNamara PJ. 2015. The impact of triclosan on the spread of antibiotic resistance in 304 the environment. Frontiers in Microbiology 5.

305 Chuanchuen R, Karkhoff-Schweizer RR, Schweizer HP. 2003. High-level triclosan resistance in 306 Pseudomonas aeruginosa is solely a result of efflux. American Journal of Infection Control $307 \quad 31: 124-127$.

308 CLSI. 2012. Methods for dilution antimicrobial susceptibility tests for bacteria that grow 309 aerobically. Approved Standard-Ninth Edition. Clinical and Laboratory Standards Institute, 310950 West Valley Rd, Ste 2500, Wayne, PA, 19087, USA.

311 DeLorenzo ME, Brooker J, Chung KW, Kelly M, Martinez J, Moore JG, Thomas M. 2016.

312 Exposure of the grass shrimp, Palaemonetes pugio, to antimicrobial compounds affects 313 associated Vibrio bacterial density and development of antibiotic resistance. Environmental $314 \quad$ Toxicology 31:469-477.

315 Edgar RC. 2004. MUSCLE: multiple sequence alignment with high accuracy and high 316 throughput. Nucleic Acids Research 32:1792-1797.

317 Garg P, Chakraborty S, Basu I, Datta S, Rajendran K, Bhattacharya T, Yamasaki S, Bhattacharya 318 SK, Takeda Y, Nair GB, Ramamurthy T. 2000. Expanding multiple antibiotic resistance 

among clinical strains of Vibrio cholerae isolated from 1992-7 in Calcutta, India.

$320 \quad$ Epidemiology and Infection 124:393-399.

321 Goh SH, Potter S, Wood JO, Hemmingsen SM, Reynolds RP, Chow AW. 1996. WSP60 gene 322 sequences as universal targets for microbial species identification: Studies with coagulase323 negative staphylococci. Journal of Clinical Microbiology 34:818-823.

324 Grimes DJ, Singleton FL, Colwell RR. 1984. Allogenic succession of marine bacterial 325 communities in response to pharmaceutical waste. Journal of Applied Bacteriology 57:247326261.

327 Guerrant RL, Carneiro BA, Dillingham RA. 2003. Cholera, diarrhea, and oral rehydration 328 therapy: Triumph and indictment. Clinical Infectious Diseases 37:398-405.

329 Guindon S, Dufayard JF, Lefort V, Anisimova M, Hordijk W, Gascuel O. 2010. New algorithms 330 and methods to estimate maximum-likelihood phylogenies: Assessing the performace of 331 PhyML 3.0. Systematic Biology 59:307-321.

332 Han F, Walker RD, Janes ME, Prinyawiwatkul W, Ge B. 2007. Antimicrobial susceptibilities of vibrio parahaemolyticus and vibrio vulnificus isolates from Louisiana gulf and retail raw oysters. Applied and Environmental Microbiology 73:7096-7098.

335 Hlady WG, Klontz KC. 1996. The epidemiology of Vibrio infections in Florida, 1981-1993. 336 Journal of Infectious Diseases 173:1176-1183.

337 Jesser KJ, Noble RT. 2018. Characterizing the ecology of Vibrio in the Neuse River Estuary, 338 North Carolina using heat shock protein 60 (hsp60) next-generation amplicon sequencing. 339 Appl Environ Microbiol. doi: 10.1128/AEM.00333-18 
340 Kearse M, Moir R, Wilson A, Stones-Havas S, Cheung M, Sturrock S, Buxton S, Cooper A,

341 Markowitz S, Duran C. 2012. Geneious Basic: an integrated and extendable desktop software

342 platform for the organization and analysis of sequence data. Bioinformatics 28:1647-1649.

343 Kitaoka M, Miyata ST, Unterweger D, Pukatzki S. 2011. Antibiotic resistance mechanisms of

344 Vibrio cholerae. Journal of Medical Microbiology 60:397-407.

345 Kwok AYC, Wilson JT, Coulthart M, Ng LK, Mutharia L, Chow AW. 2002. Phylogenetic study

346 and identification of human pathogenic Vibrio species based on partial hsp60 gene

347 sequences. Canadian Journal of Microbiology 48:903-910.

348 Lambert RJW, Pearson J. 2000. Susceptibility testing: accurate and reproducible minimum

349 inhibitory concentration (MIC) and non-inhibitory concentration (NIC) values. Journal of $350 \quad$ Applied Microbiology 88:784-790.

351 Letunic I, Bork P. 2007. Interactive Tree Of Life (iTOL): an online tool for phylogenetic tree 352 display and annotation. Bioinformatics 23:127-128.

353 Levy CW, Roujeinikova A, Sedelnikova S, Baker PJ, Stuitje AR, Slabas AR, Rice DW, Rafferty 354 JB. 1999. Molecular basis of triclosan activity. Nature 398:383-384.

355 Lydon KA, Glinski DA, Westrich JR, Henderson WM, Lipp EK. 2017. Effects of triclosan on 356 bacterial community composition and Vibrio populations in natural seawater microcosms. $357 \quad$ Elem Sci Anth 5.

358 Marder EP, Griffin PM, Cieslak PR, Dunn J, Hurd S, Jervis R, Lathrop S, Muse A, Ryan P, 359 Smith K, Tobin-D’Angelo M.,2018. Preliminary Incidence and Trends of Infections with 360 Pathogens Transmitted Commonly Through Food — Foodborne Diseases Active 361 Surveillance Network, 10 U.S. Sites, 2006-2017. MMWR Morb Mortal Wkly Rep 67:324362328. 
363 Massengo-Tiasse RP, Cronan JE. 2008. Vibrio cholerae FabV defines a new class of enoyl-acyl

364 carrier protein reductase. Journal of Biological Chemistry 283:1308-1316.

365 McMurry LM, Oethinger M, Levy SB. 1998. Triclosan targets lipid synthesis. Nature 394:531-

366532.

367 Menon M, Yu P, Iwamoto M, Painter J. 2014. Pre-existing medical conditions associated with

368 Vibrio vulnificus septicaemia. Epidemiology \& Infection 142:878-881.

369 Morgulis A, Coulouris G, Raytselis Y, Madden TL, Agarwala R, Schaffer AA. 2008. Database

370 indexing for production MegaBLAST searches. Bioinformatics 24:1757-1764.

371 Nietch CT, Quinlan EL, Lazorchak JM, Impellitteri CA, Raikow D, Walters D. 2013. Effects of

372 a chronic lower range of triclosan exposure on a stream mesocosm community.

373 Environmental Toxicology and Chemistry 32:2874-2887.

374 Okonechnikov K, Golosova O, Fursov M, team U. 2012. Unipro UGENE: a unified

375 bioinformatics toolkit. Bioinformatics 28:1166-1167.

376 Peele ER, Singleton FL, Deming JW, Cavari B, Colwell RR. 1981. Effects of pharmaceutical

377 wastes on microbial populations in surface waters at the Puerto Rico Dump Site in the

378 Atlantic-Ocean. Applied and Environmental Microbiology 41:873-879.

379 Polz MF, Hunt DE, Preheim SP, Weinreich DM. 2006. Patterns and mechanisms of genetic and

380 phenotypic differentiation in marine microbes. Philosophical Transactions of the Royal

$381 \quad$ Society B-Biological Sciences 361:2009-2021.

382 Preheim SP, Timberlake S, Polz MF. 2011. Merging taxonomy with ecological population

383 prediction in a case study of Vibrionaceae. Applied and Environmental Microbiology

$384 \quad 77: 7195-7206$. 
385 Quirke AM, Reen FJ, Claesson MJ, Boyd EF. 2006. Genomic island identification in Vibrio

386 vulnificus reveals significant genome plasticity in this human pathogen. Bioinformatics $387 \quad 22: 905-910$.

388 Reiss R, Mackay N, Habig C, Griffin J. 2002. An ecological risk assessment for triclosan in lotic 389 systems following discharge from wastewater treatment plants in the United States.

390 Environmental Toxicology and Chemistry 21:2483-2492.

391 Rivas AJ, Lemos ML, Osorio CR. 2013. Photobacterium damselae subsp damselae, a bacterium 392 pathogenic for marine animals and humans. Frontiers in Microbiology 4.

393 Rohland N, Reich D. 2012. Cost-effective, high-throughput DNA sequencing libraries for 394 multiplexed target capture. Genome Research 22:939-946.

395 Sawabe T, Kita-Tsukamoto K, Thompson FL. 2007. Inferring the evolutionary history of vibrios 396 by means of multilocus sequence analysis. Journal of Bacteriology 189:7932-7936.

397 Sawabe T, Ogura Y, Matsumura Y, Feng G, Amin AKMR, Mino S, Nakagawa S, Sawabe T, 398 Kumar R, Fukui Y, Satomi M, Matsushima R, Thompson FL, Gomez-Gil B, Christen R, 399 Maruyama F, Kurokawa K, Hayashi T. 2013. Updating the Vibrio clades defined by 400 multilocus sequence phylogeny: proposal of eight new clades, and the description of Vibrio $401 \quad$ tritonius sp nov. Frontiers in Microbiology 4.

402 Sirot J, Courvalin P, Soussy CJ. 1996. Definition and determination of in vitro antibiotic 403 susceptibility breakpoints for bacteria. Clinical Microbiology and Infection 2.

404 Slifka KMJ, Newton AE, Mahon BE. 2017. Vibrio alginolyticus infections in the USA, 1988405 2012. Epidemiology and Infection 145:1491-1499. 
406 Thompson JR, Pacocha S, Pharino C, Klepac-Ceraj V, Hunt DE, Benoit J, Sarma-Rupavtarm R, 407 Distel DL, Polz MF. 2005. Genotypic diversity within a natural coastal bacterioplankton 408 population. Science 307:1311-1313.

409 U.S. Centers for Disease Control and Prevention. 2017. Cholera and Other Vibrio Illness 410 Surveillance (COVIS). CDC, Atlanta GA.

411 U.S. Center for Disease Control and Prevention (CDC). National Surveillance of Bacterial

412 Foodborne Illnesses (Enteric Diseases): National Cholera and Vibriosis Surveillance. 2016.

413 Retrieved from the Center for Disease Control website (Accessed May 08, 2018):

414 https://www.cdc.gov/vibrio/surveillance.html

415 Wong KC, Brown AM, Luscombe GM, Wong SJ, Mendis K. 2015. Antibiotic use for Vibrio 416 infections: important insights from surveillance data. BMC Infectious Diseases 15.

417 Yazdankhah SP, Scheie AA, Hoiby EA, Lunestad BT, Heir E, Fotland TO, Naterstad K, Kruse 418 H. 2006. Triclosan and antimicrobial resistance in bacteria: An overview. Microbial Drug 419 Resistance-Mechanisms Epidemiology and Disease 12:83-90.

420 Zhu L, Lin JS, Ma JC, Cronan JE, Wang HH. 2010. Triclosan Resistance of Pseudomonas

421 aeruginosa PAO1 Is Due to FabV, a Triclosan-Resistant Enoyl-Acyl Carrier Protein 422 Reductase. Antimicrobial Agents and Chemotherapy 54:689-698. 
Figure 1 (on next page)

Phylogenetic tree of hsp60sequences of presumptive Vibrionaceaeisolates

Vibrionaceae with previously published hsp60sequences (cpnDB; http://cpndb.cal; Accessed May 02, 2018)are indicated by their genus and specific epithet (Accession Numbers Listed in Supplemental Data File 1). Branch thickness corresponds to aLRT SH-like branch support (thick line $\geq 0.5$ (most support), intermediate line $=0.5$, and thin line $\leq 0.5$ (least support)) (Guindon et al., 2010). 


\section{Vibrio mimicus ATCC 33653
Vibrio metschnikovii CIP 69.14 ATCC 700040}

Vibrio cincinnatiensis ATCC 35912
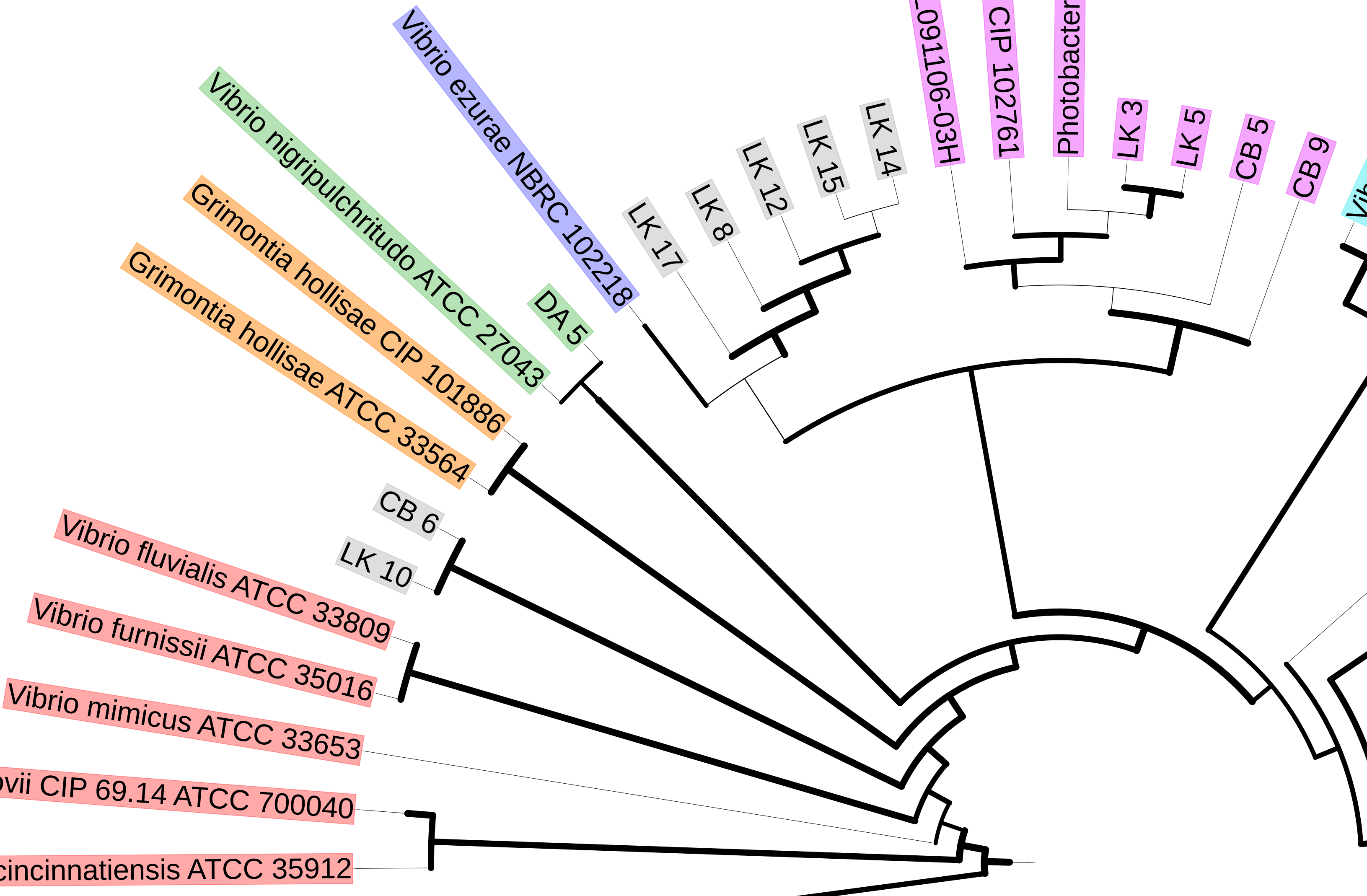

Vibrio vulnificus ATCC 27562

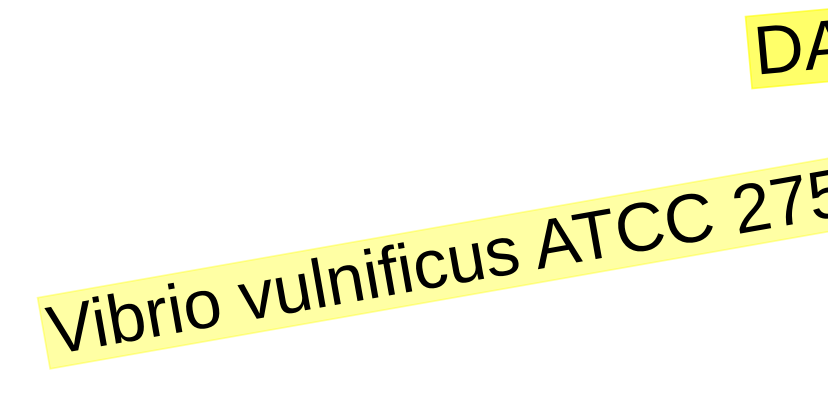




\section{Figure 2 (on next page)}

Box and whisker plot of triclosan MICs for Vibrionaceaeisolates $(n=72)$

Whiskers indicate $10-90^{\text {th }}$ percentile. E. coli was used as the control with an observed MIC of $3.1 \mu \mathrm{g} \mathrm{mL} \mathrm{L}^{-1}$. 


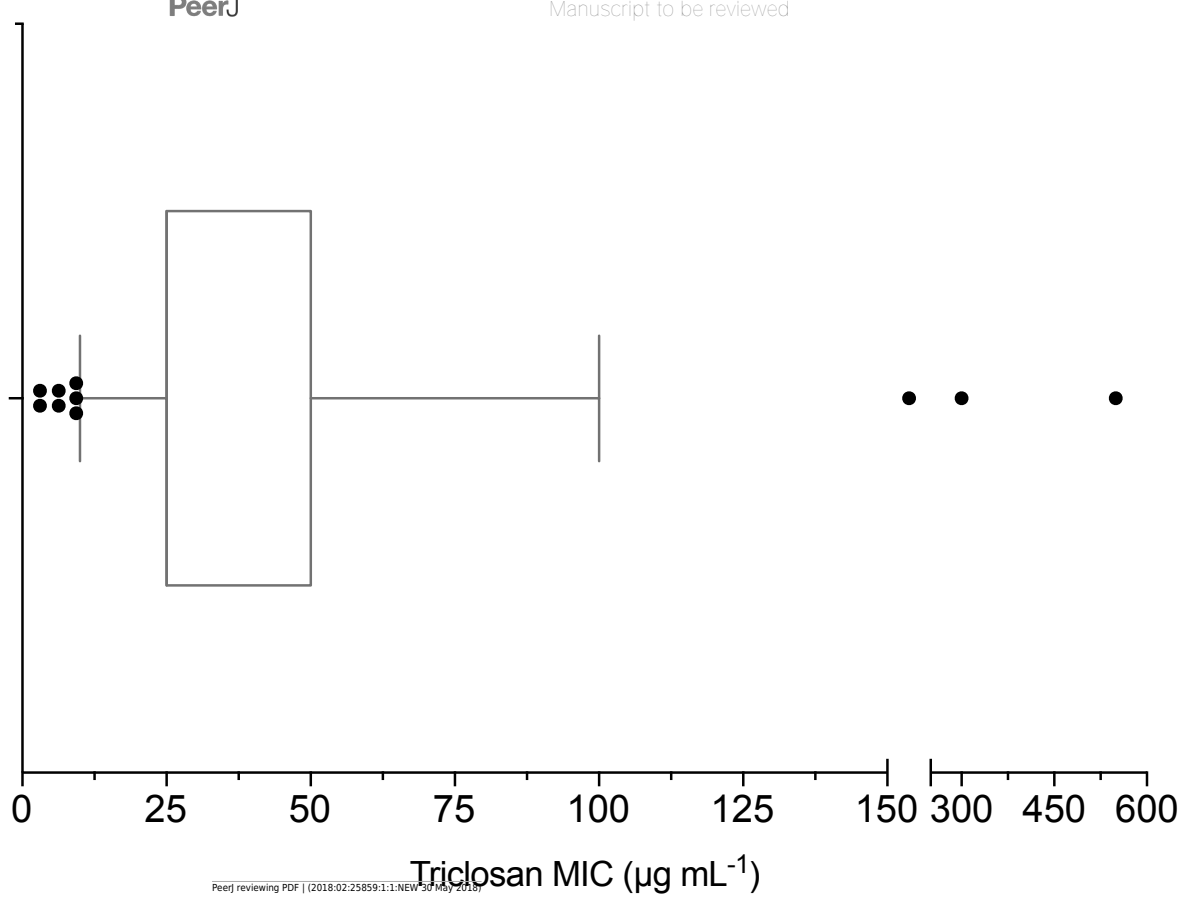




\section{Figure 3 (on next page)}

Triclosan MIC by clade, where there were greater than 3 isolates per clade

Results of one-way ANOVA demonstrated significant differences in mean rank triclosan MICS for isolates by clade $\left(F_{3,47}=4.615, p=0.0178\right)$. Tukey's post-hoc multiple comparisons tests indicated the Cholerae clade had significantly lower triclosan MICs than the Damselae (adjusted p-value=0.0178), Splendidus (adjusted p-value=0.0149), and Harveyi (adjusted pvalue $=0.0283)$ clades. 
Splendidus $(n=3)-$
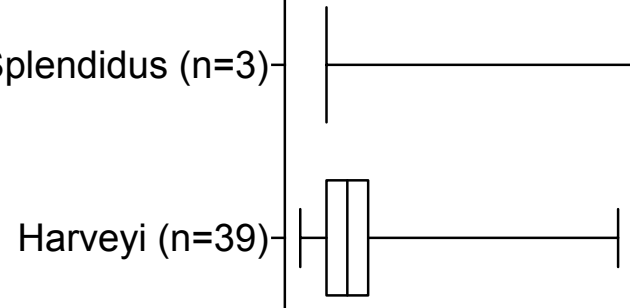

Damselae $(n=4)-$

Damselae $(n=4)-1$

Cholerae $(n=5)-$

Triclosan MIC $\left(\mu \mathrm{g} \mathrm{mL}^{-1}\right)$ 


\section{Figure 4 (on next page)}

Triclosan MIC by location sampled (Doctors Arm, Looe Key, and Clambank Landing)

Results of one-way ANOVA showed no significant differences in triclosan MICs for Vibrionaceae by location sampled $\left(F_{2,51}=1.346, p=0.2694\right)$. 


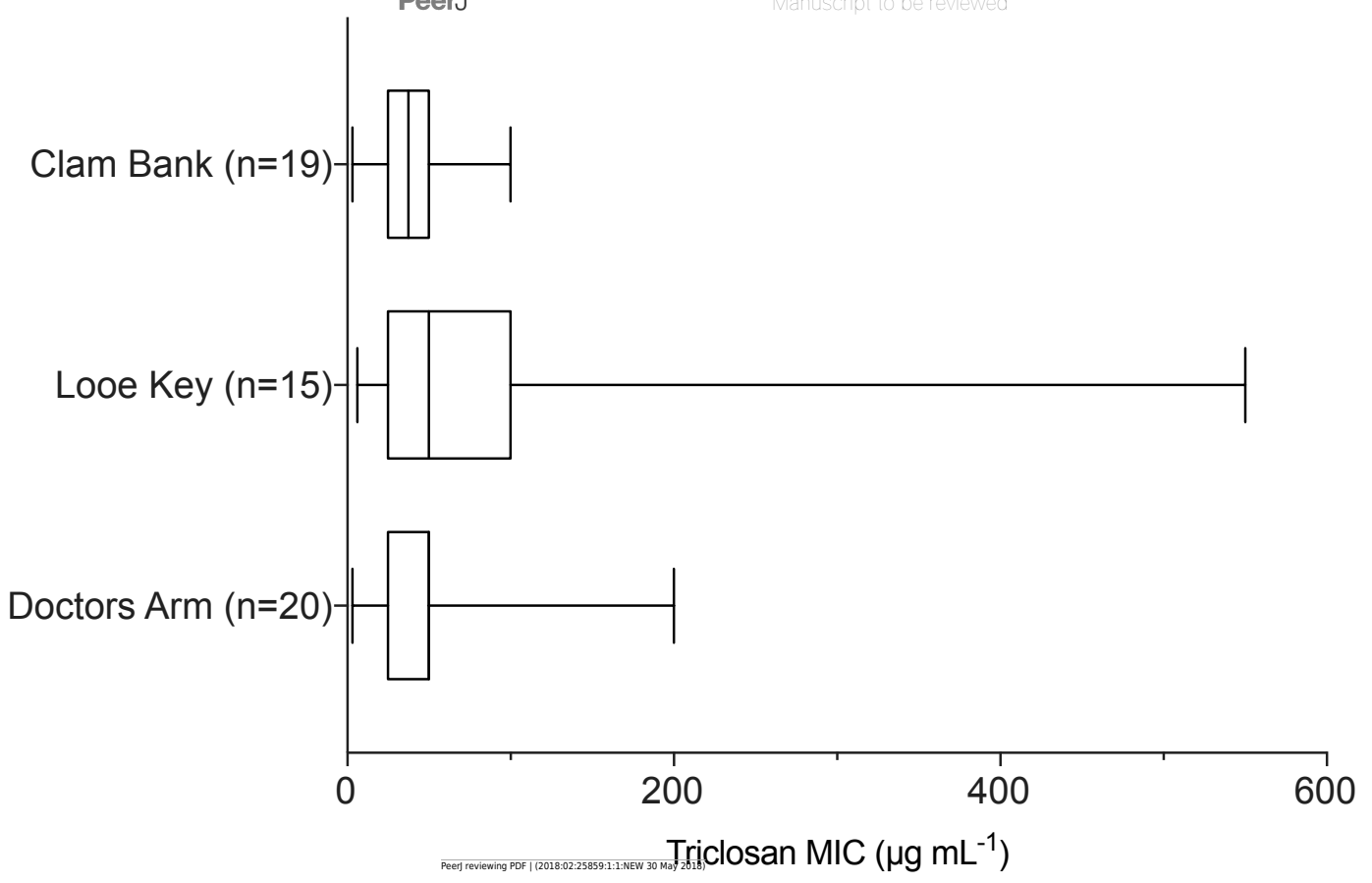




\section{Figure $\mathbf{5}$ (on next page)}

Triclosan MIC by species within the Harveyi clade where there were greater than 3 isolates per species tested

Results of one-way ANOVA showed no significant differences ( $p>0.05$ ) in triclosan MICs among these species $\left(F_{2,27}=0.2448, p=0.7846\right)$. 


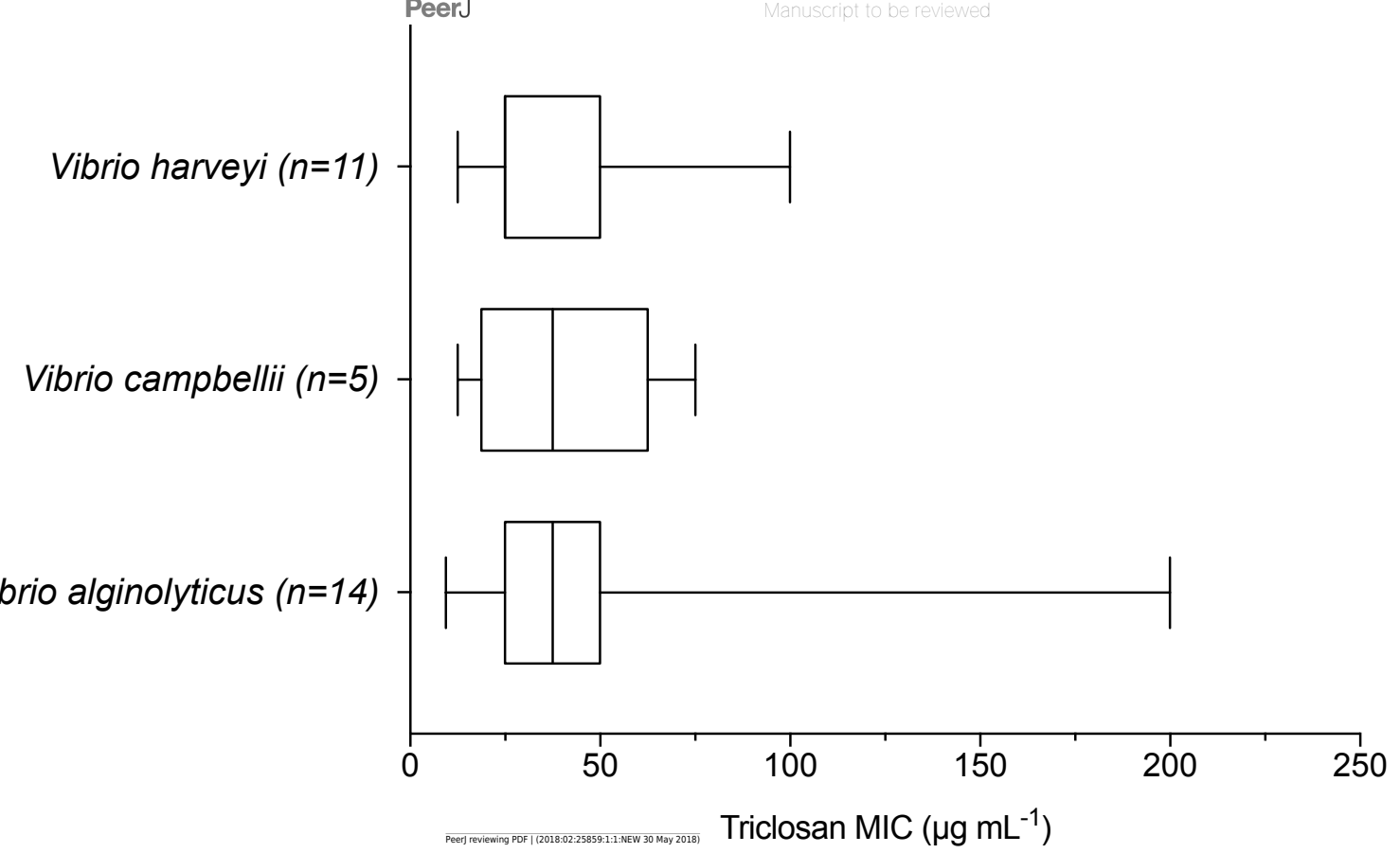

